\title{
PENGENALAN PLAT NOMOR POLISI KENDARAAN BERMOTOR
}

\author{
Ottopianus Mellolo ${ }^{1)}$ \\ ${ }^{1)}$ Program Studi Teknik Elektro Politeknik Manado \\ e-mail: ottopianus.mellolo@yahoo.com
}

\begin{abstract}
ABSTRAK
Penelitian ini bertujuan membuat sistem yang dapat mengenali karakter pada plat nomor polisi kendaraan yang terdapat pada citra digital. Sampel yang digunakan sebanyak 50 citra uji terdiri atas 25 citra kendaraan pribadi dengan warna dasar plat hitam tulisan putih, 10 citra kendaraan dinas pemerintah dengan warna dasar plat merah tulisan putih, dan 15 citra angkutan umum dengan wara dasar plat kuning tulisan hitam. Adapun Penelitian ini dilakukan melalui beberapa tahap, yaitu (1) Pengolahan Citra, untuk mempersiapkan citra dan mengambil fitur - fitur penting yang akan digunakan pada tahap - tahap selanjutnya (2) Penentuan Region of Interest (ROI) yaitu penentuan posisi plat nomor dalam citra, (3) Segmentasi Karakter yaitu membagi citra plat nomor menjadi citra yang memuat satu karakter, dan (3) pengenalan karakter yaitu mencocokkan karakter yang dicari dengan karakter referensi untuk dikenali. Hasil penelitian menunjukkan bahwa sistem dapat mengenali karakter pada plat nomor polisi kendaraan bermotor untuk ketiga jenis plat nomor dengan persentase rata-rata sebesar 79,43\%.
\end{abstract}

Kata kunci: Citra, pengenalan, plat nomor polisi

\section{MOTORIZED VEHICLE POLICE NUMBER PLATE RECOGNITION}

\begin{abstract}
The research is aimed to create one system in recognize the characteristic of the motor vehicle plate number that has digital image. The number of samples used was 50 test image consisted of 25 private vehicle images with written white numbers on the black base plate, 10 govemment vehicle image with written white numbers on the red base plate and 15 public vehicle images with black written numbers on the yellow base plate. The research undenrwent several stages :(1) Image processing to prepare image and get the important features to be used for next stages (2) Determining Region of Interest (ROl), determining plate position in image, (3) Character segmentation, dividing plate number image which can only accomodate one character ; and (4)Character recognition, character verification that is sought with reference character to be recognized. The results indicatet hat the system can recognize the characters on the motor vehicle police plate number for the three types of the plate numbers with the average percentage $79,43 \%$.
\end{abstract}

Keywords: Image, recognition, police plate number

\section{PENDAHULUAN}

Salah satu bagian unik dari sebuah kendaraan bermotor adalah plat nomor polisi kendaraan tersebut yang secara formal disebut Tanda Nomor Kendaraan Bermotor (TNKB), plat nomor polisi merupakan identitas utama dari sebuah kendaraan bermotor yang laik jalan/beroperasi di jalan raya, sehingga plat nomor polisi umumnya diletakkan pada posisi yang mudah dilihat.

Manusia berusaha mengadopsi bentuk kecerdasan yang dimilikinya kedalam computer, kecerdasan yang dimiliki oleh komputer inilah yang seringkali disebut kecerdasan buatan seperti dalam kemampuan mengenali sesuatu, membedakan satu bentuk dengan bentuk lainnya bahkan mengenali karakter yang terdapat dalam citra.

Merujuk pada penelitian yang dilakukan oleh Martinsky dengan judul Algoritmic and Mathematical Principle of Automatic Number Plate Recognition Systems dengan JavaANPR perangkat lunak yang digunakan untuk mengenali plat nomor polisi yang terdapat dalam citra kendaraan (plat dasar putih/terang tulisan hitam/gelap 
umumnya digunakan oleh negara negara Eropa Tengah), JavaANPR merupakan perangkat lunak open source sehingga dapat digunakan maupun dimodifikasi sesuai dengan kebutuhan sepanjang dilakukan untuk tujuan akademis (non komersil). Penulis mencoba untuk melakukan pengembangan menggunakan paket JavaANPR ini agar dapat digunakan mengenali plat nomor polisi yang dipakai di Indonesia dengan fokus utama pada jenis plat kendaraan bermotor yang banyak digunakan yaitu plat hitam pada kendaraan pribadi, plat merah pada kendaraan dinas pemerintah dan plat kuning pada kedaraan angkutan umum.

\section{TINJAUAN PUSTAKA}

\section{Citra Digital}

Citra digital dapat dinyatakan sebagai suatu fungsi dua dimensi $f(x, y)$, dengan $x$ maupun y adalah posisi koordinat sedangkan $\mathrm{f}$ merupakan amplitudo pada posisi $(\mathrm{x}, \mathrm{y})$ yang sering dikenal sebagai intensitas atau grey scale. Nilai dari intensitas bentuknya adalah diskrit mulai dari 0 sampai 255. Citra digital dapat dinyatakan dengan matriks berukuran $\mathrm{N}$ x M (baris/tinggi $=\mathrm{N}$, kolom/lebar $=\mathrm{M})$.

$\left[\begin{array}{rllc}f(0,0) & f(0,1) & \ldots & f(0, M-1) \\ f(1,0) & f(1,1) & & f(1, M-1) \\ & \vdots & \ddots & \vdots \\ f(N-1,0) & f(N-1,1) & \cdots & f(N-1, M-1)\end{array}\right] \ldots . .(1)$

dimana :

$\mathrm{N}=$ jumlah baris $0 \leq y \leq N-1$

$\mathrm{M}=$ jumlah kolom $0 \leq x \leq M-1$

$\mathrm{L}=$ maks warna intensitas $0 \leq f(x, y) \leq L-1$

(derajat keabuan / gray level) (Putra, 2010).

Pembentukan citra digital (diskrit) melalui beberapa tahapan yaitu akuisisi citra, sampling, dan kuantisasi. Proses akuisisi citra adalah pemetaan suatu pandangan menjadi citra kontinu dengan menggunakan sensor. Tahap berikutnya adalah proses sampling yaitu proses digitasi pada koordinat $\mathrm{x}, \mathrm{y}$ seperti yang disebutkan diatas hasil dari sensor masih berupa citra kontinu yang merupakan fungsi kontinu $\mathrm{f}(\mathrm{x}, \mathrm{y})$ (Putra, 2010).

\section{Pengolahan Citra Digital}

Pengolahan citra (image processing) merupakan proses mengolah piksel-piksel didalam citra digital untuk tujuan tertentu.
Pengolahan citra dilakukan karena beberapa alasan yaitu untuk mendapatkan citra asli dari suatu citra yang mengalami penurunan kualitas karena pengaruh derau atau untuk memperoleh citra dengan karakteristik dan cocok secara visual yang dibutuhkan untuk tahap lebih lanjut dalam proses analisis citra.

Operasi deteksi tepi objek merupakan operasi yang mendeteksi perubahan tingkat keabuan yang signifikan dari suatu citra (Purnomo dan Muntasa, 2010 ). Deteksi tepi biasa digunakan untuk memisahkan atau paling tidak memperjelas batas antara suatu objek dengan objek lainnya (Suarga, 2008). Proses ini dilakukan dengan cara menelusuri citra secara vertikal dan horisontal untuk menemukan perbedaan nilai yang signifikan antara suatu piksel dengan piksel tetangganya. Ada beberapa operator yang dikembangkan berdasarkan turunan pertama diantaranya Sobel, Roberts, Prewitt, dan canny. Operator Sobel terdiri dari matriks $3 \times 3$ masing masing adalah $G_{x}$ dan $G_{y}$ matriks konvolusi tersebut dirancang untuk memberikan respon secara maksimal terhadap tepi objek baik horisontal maupun vertikal. konvolusi dapat diaplikasikan secara terpisah terhadap input citra (Purnomo dan Muntasa, 2010 ). Operator sobel dapat dituliskan seperti berikut ini:

$$
\begin{aligned}
G_{x} & =\left[\begin{array}{lll}
-1 & 0 & 1 \\
-2 & 0 & 2 \\
-1 & 0 & 1
\end{array}\right] \ldots \ldots \\
G_{y} & =\left[\begin{array}{ccc}
-1 & -2 & -1 \\
0 & 0 & 0 \\
1 & 2 & 1
\end{array}\right] \ldots
\end{aligned}
$$

untuk mendapatkan gradien gabungan dapat dihitung dengan menggunkan persamaan :

$$
G[f(x, y)]=\sqrt{G_{x}^{2}+G_{y}^{2}}
$$

\section{Transformasi Citra}

Pada dasarnya ada empat macam transformasi, yaitu scala, rotation, translation, dan shear (Suarga, 2008 ). Hough transform adalah teknik transformasi citra yang dapat digunakan untuk mengisolasi objek pada suatu citra dengan menemukan batasbatasnya. Classical Hough transform merupakan teknik yang paling umum digunakan untuk mendeteksi objek yang berbentuk kurva seperti garis,lingkaran, ellips dan parabola (Putra, 2010). 


\section{Pengambangan}

Proses pengambangan (thresholding) citra grayscale secara umum menggunakan rumus $g(x, y)=\left\{\begin{array}{l}1 \text { jika } f(x, y) \geq T \\ 0 \text { jika } f(x, y)<T\end{array}\right.$

Nilai $\mathrm{g}(\mathrm{x}, \mathrm{y})$ adalah citra biner yang dihasilkan dari citra grayscale $\mathrm{f}(\mathrm{x}, \mathrm{y})$, nilai $\mathrm{T}$ adalah nilai ambang. Nilai $\mathrm{T}$ sangat menentukan kualitas citra biner yang dihasilkan. Ada dua jenis pengambangan yaitu pengambangan global dan pengambangan lokal adaptif

Pengambangan lokal adaptif dilakukan dengan cara membagi citra kedalam blokblok, kemudian dilakukan pengambangan lokal pada setiap blok dengan nilai $\mathrm{T}$ yang berbeda. Dapat dihitung dengan rumus

$T=\frac{\sum(x, y) \in W \sum f(x, y)}{N_{w}}-c$

Dimana $W$ menyatakan blok yang diproses, $N_{W}$ menyatakan banyaknya piksel pada setiap blok W dan $c$ menyatakan suatu konstanta

\section{Negasi / Invert}

Negasi merupakan operasi mendapatkan citra negatif (Negatif Image) suatu citra seperti halnya meniru film negatif pada fotografi, yaitu titik yang berwarna putih pada citra warna hitam pada film negatifnya, demikian juga sebaliknya dengan cara mengurangi nilai intensitas pixel dari nilai keabuan maksimum. Misalnya citra dengan 256 derajat keabuan (8 bit). citra negatif diperoleh dengan persaman.

$$
f(x, y)^{\prime}=255-f(x, y)
$$

\section{Pengenalan Pola}

Pengenalan pola adalah mengelompok-kan data numerik dan simbolik secara otomatis oleh mesin (komputer) dengan untuk mengenali suatu objek di dalam citra. Manusia bisa mengenali objek yang dilihatnya karena otak manusia telah belajar mengklasifikasi objek-objek di alam sehingga mampu membedakan suatu objek dengan objek lainnya. Kemampuan sistem visual manusia yang dicoba ditiru oleh mesin (Putra Darma. 2010).

\section{Plat Nomor Polisi Kendaraan Bermotor}

Plat Nomor

Tanda Nomor Kendaraan Bermotor berbentuk plat dengan cetakan tulisan dua baris.
- Baris pertama menunjukkan: kode wilayah (huruf), nomor polisi (angka), dan kode/seri akhir wilayah (huruf)

- Baris kedua menunjukkan bulan dan tahun masa berlaku

TNKB adalah plat aluminium yang berdimensi $250 \times 105 \times 1 \mathrm{~mm}$, Pada sisi kanan dan kiri terdapat tulisan DITLANTAS POLRI, contoh TNKB jenis plat Hitam, Kuning dan Merah dapat dilihat pada gambar 1.

\section{DDT083UADD1725AY DD 257 AT
(a)
(b)
(c)

Gambar 1 Plat Nomor Polisi Kendaraan bermotor jenis (a) plat hitam, (b) plat kuning dan (c) plat merah

\section{Aturan Penomoran}

Nomor polisi diberikan sesuai dengan urutan pendaftaran kendaraan bermotor. terdiri dari 1-4 angka, ditempatkan setelah kode wilayah pendaftaran. Apabila nomor urut pendaftaran yang telah dialokasikan habis digunakan, maka nomor urut pendaftaran berikutnya kembali ke nomor awal yang telah dialokasikan dengan diberi tanda pengenal huruf seri $\mathrm{A}-\mathrm{Z}$ di belakang angka pendaftaran. Kode wilayah pendaftaran kendaraan bermotor ditetapkan berdasarkan Peraturan Kapolri Nomor 4 Tahun 2006. Kode nomor polisi diawali dengan satu atau dua huruf didepan seperti untuk wilayah Sulawesi DB untuk Sulawesi Utara Daratan, DL untuk Sulawesi Utara Kepulauan, DM untuk Gorontalo, DN untuk Sulawesi Tengah , DT untuk Sulawesi Tenggara, DD untuk Sulawesi Selatan ,DC untuk Sulawesi Barat

\section{METODOLOGI PENELITIAN}

Alur sistem pengenalan plat nomor polisi kendaraan bermotor secara garis besar terbagi atas empat tahap seperti pada gambar 2.

\section{Tahap Pengolahan Citra}

Pengolahan citra merupakan proses manipulasi terhadap file citra untuk mendapatkan fitur - fitur penting yang dapat digunakan sebagai indikator dalam proses pegenalan (plat nomor polisi kendaraan bermotor). Adapun format file citra yang digunakan pada penelitian ini adalah JPEG. 
agar mudah dimodifikasi citra dibawa dalam bentuk BufferedImage. Sistem koordinat warna yang ada pada citra masukan masih berbentuk koordinat RGB (Red, Green, Blue) dimana setiap piksel memiliki tiga nilai warna. koordinat ini kemudian dikonversi ke bentuk HSB (Hue, Saturation, Brightnes). untuk mendapatkan magnitude (nilai brightness). Serangkaian operasi enhance masih tetap diberlakukan terhadap citra setiap sebelum masuk pada tahap - tahap selanjutnya seperti proses duplikasi/clon untuk memudahkan proses pengolahan dan manipulasi terhadap setiap piksel dalam citra tanpa merusak citra aslinya. Normalisasi nilai brightness, resize untuk menyesuaikan ukuran citra, pengambangan adaptif (Adaptive Tresholding), Tepian dari citra dapat merepresentasikan objek-objek yang terkandung didalamnya dalam hal ini plat nomor polisi kendaraan, deteksi tepi dengan menggunakan operator sobel secara vertical sehingga memberikan perbedaan tepian yang lebih jelas, sedangkan Transformasi Hough digunakan untuk mendeteksi, memperbaiki kemiringan maupun rotasi citra (Martinsky, 2007).

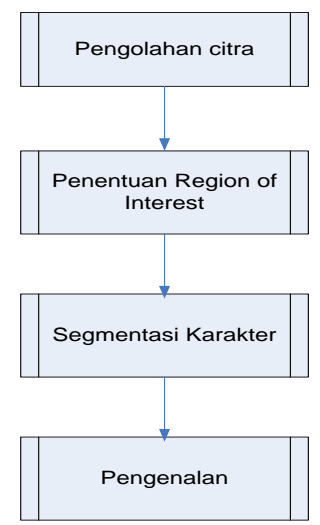

Gambar 2. Struktur umum sistem pengenalan plat nomor polisi kendaraan bermotor

\section{Tahap Penentuan Region of Interest (ROI)}

Menentukan Region of Interest merupakan fase awal yang sangat menentukan dari proses identifikasi plat nomor secara keseluruhan, kegagalan proses penentuan ROI menyebabkan sistem pengenalan tidak dapat memberikan hasil yang kita harapkan.

\section{Deteksi ROI vertikal}

Deteksi secara vertikal bertujuan untuk menentukan posisi plat secara vertikal, pada proses ini akan diambil beberapa potongan berupa pita yang terindikasi memuat plat nomor kendaraan dalam citra, Berangkat dari asumsi dasar bahwa sebuah plat merupakan identitas bagi sebuah kendaraan dengan demikian identitas ini akan ditempatkan pada posisi yang mudah dilihat, dengan tulisan yang jelas terbaca. Citra sebuah plat yang berisi beberapa karakter tentunya akan memperlihatkan frekuensi tepian yang tinggi setelah citra kendaraan tersebut dideteksi tepi seperti pada gambar 3 .

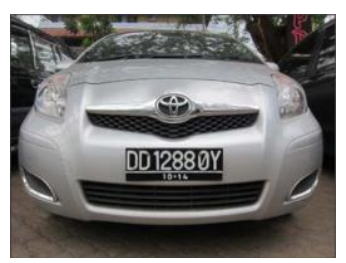

(a)

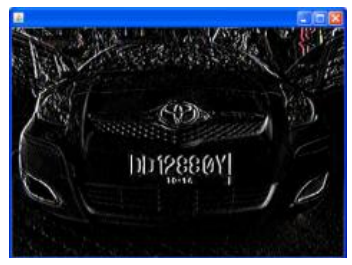

(b)
Gambar 3. (a)citra asli (b)Hasil deteksi tepi

Nilai magnitude dari citra kemudian di proyeksikan sehingga membentuk histogram proyeksi vertikal(Martinsky, 2007), Misalkan citra masukan dengan lebar $l$ dan tinggi $t$, proyeksi vertikal $P_{y}(x)$ dari fungsi $\theta(\mathrm{x}, \mathrm{y})$ di titik $y$ adalah jumlahan dari semua magnitude pixel dalam baris ke $y$, secara matematis proyeksi vertikal dapat didefinisikan sebagai :

$\left.P_{y}(x)=\sum_{x=0}^{l-1} \theta(x, y)\right)$

dimana $\theta(x, y)$ adalah magnitude piksel pada koordinat $(x, y)$ dan $y=0 \ldots(t-1)$

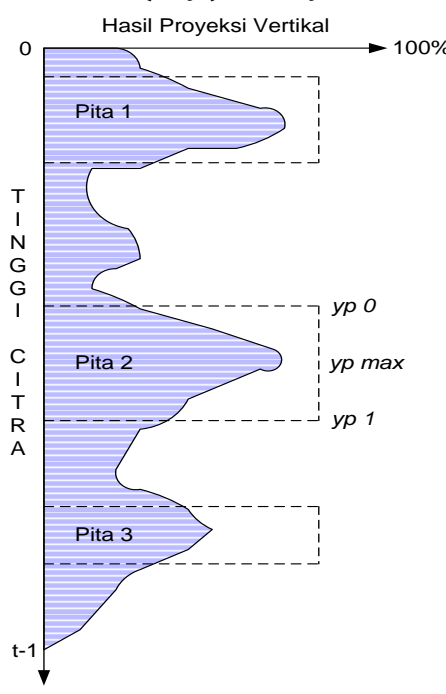

Gambar 4. Grafik proyeksi vetikal 
Daerah pada plat dengan frekuensi yang tinggi ditandai dengan adanya puncak puncak pada histogram, ilustrasi proyeksi vertikal dapat dilihat pada gambar 4 yang memperlihatkan tiga buah puncak terindikasi kemungkinan merupakan posisi plat secara vertikal. Dengan mengacu pada indikator ini citra kemudian dipotong secara horisontal sehingga membentuk sekumpulan pita. Persoalan berikutnya adalah menghitung puncak dalam grafik proyeksi vertikal. Puncak bersesuaian dengan pita - pita kandidat yang mungkin adalah plat nomor seperti terlihat pada gambar 4 Nilai maksimum dari $P_{y}(x)$ bersesuaian dengan poros dari pita dan dapat dihitung sebagai

$$
y_{p \text { maks }}=\operatorname{maks}_{0<y<t-1}\left\{P_{y}(x)\right\} \ldots \ldots \ldots \ldots \text { (7) }
$$

Pada $y_{p 0}$ dan $y_{p 1}$ adalah koordinat dari pita, yang dapat dideteksi sebagai :

$$
\begin{aligned}
& y_{p 0}=\min _{0 \leq y \leq t-1}\left\{y \mid P_{y}(x) \leq k_{y} \cdot P_{y_{p \text { maks }}}(x)\right\} \\
& y_{p 1}=\operatorname{maks}_{0 \leq y \leq t-1}\left\{y \mid P_{y}(x) \leq k_{y} \cdot P_{y_{p \text { maks }}}(x)\right\}
\end{aligned}
$$

$k_{y}$ adalah sebuah konstanta pengali untuk menentukan kaki dari puncak $y_{p \text { maks }}$ pemakaian konstanta ini diterapkan secara iteratif untuk mendeteksi beberapa kemungkinan posisi plat secara vertikal. $y_{p 0}$ dan $y_{p 1}$ adalah koordinat yang dihitung dalam setiap langkah proses iterasi(Martinsky, 2007). Setelah deteksi, nilai-nilai proyeksi $P_{y}$ dalam interval $[0, t-1]$

Pada penelitian ini kita menggunakan tiga jenis plat dengan warna dasar yang berbeda yaitu hitam,merah dan kuning sedangkan tulisan yang dipakai ada dua yaitu putih dan hitam. Secara default sistem ini hanya dapat mengenali plat dengan tulisan hitam (gelap), latar belakang putih (terang), sistem ini tidak perlu diubah tetapi cukup ditambahkan proses lain untuk mengcover jenis plat hitam tulisan putih dan jenis plat merah tulisan putih. berangkat dari keadaan ini maka sebelum masuk dalam tahap berikut pita - pita yang telah dipotong ini harus dibuatkan invertnya dengan asumsi bahwa jika terjadi kemungkinan citra yang akan dikenali adalah citra kendaraan plat hitam atau merah sistem tetap dapat mengenlinya dari inver citranya. Proses inverting citra akan menghasilkan citra dengan tulisan plat berwarna hitam dengan latar terang atau putih. Pita pita ini kemudian dikumpulkan untuk dianalisis lebih lanjut satu persatu.

\section{Deteksi ROI Horizontal}

Deteksi secara horisontal bertujuan untuk menentukan posisi plat secara horisontal dari pita yang telah diperoleh pada proses deteksi secara vertikal diatas. Analisis prioritas digunakan untuk menentukan urutan pengerjaan dari potongan pita, ada beberapa parameter yang menjadi penentu dalam proses ini yaitu : tinggi pita, tinggi maksimum puncak, luas dari puncak, perbandingan panjang dan lebar plat nomor. Paramenter ini dihitung secara statistik dengan formula sebagai berikut :

tinggi pita $\alpha_{1}=\left|y_{p 0}-y_{p 1}\right| \ldots \ldots \ldots . .(8)$

tinggi maks pita $\alpha_{2}=\frac{1}{P_{y}\left(y_{p \text { maks }}\right)} \ldots \ldots$...

luas puncak $\alpha_{3}=\frac{1}{\sum_{y p 0}^{y p 1} P_{y}} \ldots \ldots \ldots \ldots \ldots$

perbandingan panjang dan lebar plat nomor $\alpha_{4}=\left|\frac{l}{\left|y_{p 0}-y_{p 1}\right|}-5\right|$

pita dengan nilai total $\alpha$ terkeci yang akan diprioritaskan terlebih dahulu. Potongan potongan pita kemudian dianalisis untuk mendapatkan posisi plat nomor yang diinginkan Jika $l$ adalah lebar dari pita (= lebar citra yang dianalisis) dan t adalah tinggi dari pita hubungan dengan proyeksi horisontal $P_{x}(y)$ Hal ini dapat diperoleh dari penjumlahan dalam interval $\left[y_{p 0}, y_{p 1}\right]$, yang merupakan batas-batas vertikal dari pita.

$$
P_{x}(y)=\sum_{y=o}^{t-1} \theta(x, y)
$$

Setelah melalui operasi konfolusi seperti pada pencarian pita jumlah nilai magnitude diproyeksikan horisontal $P_{x}(y)$. Hasil proyeksi jumlah magnitude secara horizontal dapat diilustrasikan seperti pada gambar 5 :

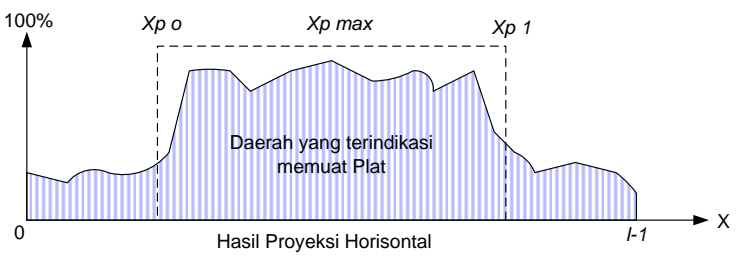

Gambar 5. Grafik proyeksi horisontal

nilai maksimum sesuai dengan plat dapat dihitung sebagai:

$$
x_{p \text { maks }}=\operatorname{maks}_{0 \leq x \leq l-1}\left\{P_{x}(y)\right\}
$$

$x_{p 0}$ dan $x_{p 1}$ adalah koordinat dari plat yang dapat dideteksi sebagai :

$$
x_{p 0}=\min _{0 \leq x \leq l-1}\left\{x \mid P_{x}(y) \leq k_{x} \cdot P_{x_{p \text { maks }}}(y)\right\}
$$




$$
x_{p 1}=\min _{0 \leq x \leq l-1}\left\{x \mid P_{x}(y) \leq k_{x} \cdot P_{x_{p \text { maks }}}(y)\right\}
$$

Dimana $k_{x}$ adalah konstanta yang dapat digunakan untuk menentukan kaki dari puncak $x_{p \text { maks }} \quad$ (Martinsky, 2007).

\section{Segmentasi Karakter}

Potongan plat nomor yang telah diperoleh belum dapat diketahui karakter apa yang terdapat didalamnya, berapa banyak dan apa jenis karakternya, sehingga potongan plat tersebut harus disegmentasi lagi menjadi beberapa segmen/bagian yang lebih kecil dimana setiap segmen yang hanya memuat satu buah karakter saja. Untuk mendeteksi dan memisahkan satu potong karakter dari potongan lainnya, potongan plat terlebih dahulu diproyeksikan horizontal, semua citra yang sampai pada tahap ini hanya akan memuat tulisan gelap dengan latar terang sehingga pada hasil proyeksi akan terlihat frekuensi yang berfluktuasi, setiap puncak dari histogram proyeksi diasumsikan sebagai ruang antar karakter pada potongan plat (Martinsky, 2007)

\section{Tahap pengenalan karakter}

Setelah setiap karakter tersegmentasi dengan baik, citra resampling tersebut kemudian diskeletonkan dengan menggunakan metode transformasi sumbu tengah (medial axis transform). Proses pengenalan terhadap setiap karakter menggunakan metode Euclidian Distance Pattern matching dimana vector dari sebuah karakter yang telah tersegmentasi dengan baik kemudian dicari jarak Euclidian dengan karakter referensi yang telah disiapkan, pola karakter masukan yang mempunyai jarak ecludian terkecil terhadap pola referensi yang akan diasosiasikan dengan karakter referensi tersebut. Pola karakter referensi ini mewakili setiap karakter angka dari 0 sampai 9 dan karakter huruf dari A sampai $\mathrm{Z}$ dengan ukuran 8 x 13 piksel . (Martinsky, 2007).

\section{Tampilan Interface}

Untuk memudahkan interaksi pengguna dengan sistem (friendly user) maka desain antar muka tampilannya dibuat seperti gambar 6.

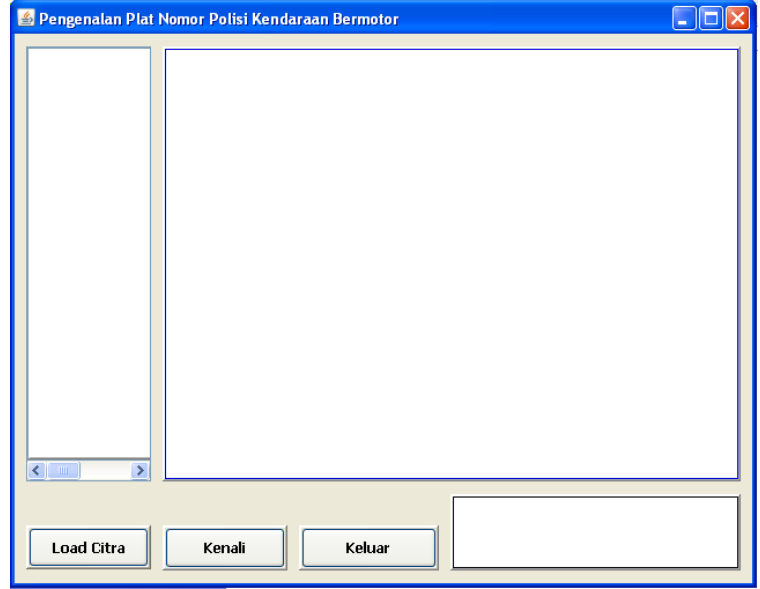

Gambar 6. Tampilan interface sistem pengenalan plat nomor

\section{HASIL DAN PEMBAHASAN}

\section{Citra masukan}

Kendaraaan yang di ambil citranya adalah kendaraan pribadi dengan warna dasar plat hitam tulisan putih, kendaraan dinas pemerintah dengan warna dasar plat merah tulisan putih dan kendaraan umum dengan warna dasar plat kuning tulisan hitam, Seperti pada sampel citra kendaraan dibawah ini:

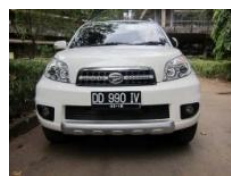

(a)

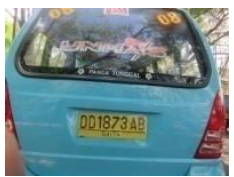

(b)

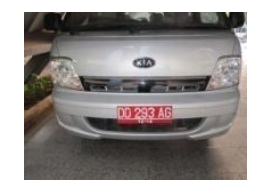

(c)
Gambar 7.Sampel Citra kendaraan (a)Plat Hitam h4.jpg (b) Plat Kuning k1.jpg dan (c)

Plat Merah m3.jpg

Citra yang dipakai formatnya dalam bentuk JPEG dengan ukuran 500 x 375 piksel, Citra - citra tersebut disimpan dalam sebuah folder dengan inisialisasi nama hn.jpg, kn.jpg, $\mathrm{mn}$.jpg untuk file citra plat hitam, kuning dan merah. untuk memperoleh citra hasil yang baik kendaraan dipotret dari jarak yang dekat atau dengan zooming agar plat nomor yang ada di dalam citra dapat terbaca dengan jelas pada penelitian ini kendaraan yang di capture sebanyak 50 citra dengan komposisi plat hitam sebanyak 25 buah, plat merah sebanyak 10 buah, dan plat kuning sebanyak 15 buah. Sebahagian besar huruf depan dari plat nomor dalam citra sampel diawali dengan kode wilayah DD karena penelitian ini 
dilaksanakan di kota Makassar Sulawesi Selatan.

\section{Menentukan Region of Interest (ROI)}

Plat nomor adalah sasaran utama dalam sistem pengenalan ini(ROI), persentase keberhasilan sistem ditentukan oleh kemampuan sistem menemukan potongan plat yang terdapat dalam citra, hasil penentuan ROI untuk ketiga jenis plat dapat dilihat pada tabel 1.

Tabel 1. Hasil penentuan ROI

\begin{tabular}{|l|l|c|}
\hline \multirow{2}{*}{ No } & \multicolumn{1}{|c|}{ Jenis Plat } & Persentase \% \\
& & \\
\hline 1 & Plat Hitam & 100,00 \\
2 & Plat Merah & 90,00 \\
3 & Plat Kuning & 100,00 \\
\hline \multicolumn{2}{|c|}{ Rata - rata } & 96,67 \\
\hline
\end{tabular}

Untuk kasus dimana sistem tidak dapat menemukan ROI hal ini disebabkan oleh banyaknya iluminasi cahaya pada citra yang menghasilkan bayangan,akibatnya pada saat dideteksi tepi akan menghasilkan pola sebaran magnitude yang merata sehingga mengaburkan informasi posisi plat nomor dalam citra. Contoh kasus citra kendaraan bermotor yang dapat ditemukan ROI nya dapat dilihat pada gambar 8 .

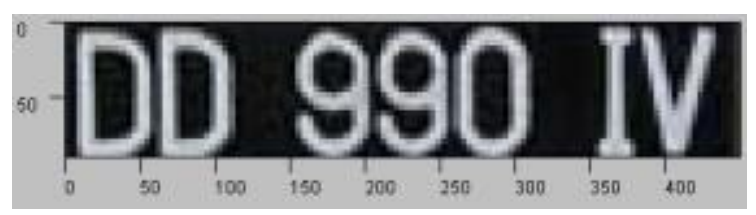

Gambar 8. ROI dari citra h4.jpg

\section{Segmentasi Karakter}

Bahagian yang merupakan region of interest dari tahap sebelumnya kemudian dipotong / disegmentasi menjadi potongan citra yang hanya memuat satu karakter pada setiap citra, persentase keberhasilan sistem pada tahap ini terletak pada keberhasilan sistem melakukan segmentasi terhadap setiap karakter yang terdapat pada citra plat, adapun hasil segmentasi karakter dari citra plat dapat dilihat pada tabel 2 .
Tabel 2. Hasil Segmentasi karakter

\begin{tabular}{|c|l|c|}
\hline \multirow{2}{*}{ No } & Jenis Plat & Persentase \% \\
\hline 1 & & \\
2 & Plat Hitam & 94,48 \\
3 & Plat Merah & 79,52 \\
\hline \multicolumn{2}{|c|}{ Rat Kuning - rata } & 90,32 \\
\hline
\end{tabular}

Untuk kasus citra yang tidak ditemukan ROI nya jelas tidak akan sampai pada tahap segmentasi karakter disisi lain walaupun ROI berhasil ditemukan dan benar hal ini belum serta - merta membuat proses segmentasi karakter berhasil hal ini disebabkan karena kemungkinan bentuk karakter yang tidak jelas/cacat, adanya iluminasi cahaya yang tidak seragam dan banyak factor - factor lain yang ikut mempengaruhi citra sehingga interpretasi citra oleh sistem menjadi keliru. Proses segmentasi ini bertujuan menentukan batas - batas sebuah karakter untuk dipotong menjadi citra baru sampai citra hanya memuat satu karakter. Contoh kasus citra yang tersegmentasi dengan baik dapat dilihat pada gambar 9.

\section{IDDI990IIV \\ Gambar 9. Hasil Segmentasi dari citra h4.jpg}

\section{Pengenalan Karakter}

Pengenalan karakter adalah tahap akhir dari serangkaian proses pengenalan plat nomor polisi kendaraan bermotor. Citra hasil segmentasi kemudian dianalisis untuk mengenali jenis karakter yang ada didalam citra. Persentase keberhasilan sistem untuk menentukan hasil pengenalan diperoleh dengan memperbandingkan hasil output yang dikeluarkan oleh sistem dengan setiap karakter yang terdapat pada citra secara visual. Hasil pengenalan karakter dapat dilihat pada tabel 3 .

Tabel 3. Hasil Pengenalan karakter

\begin{tabular}{|l|l|c|}
\hline \multirow{2}{*}{ No } & Jenis Plat & Persentase \% \\
\hline 1 & Plat Hitam & 69,52 \\
2 & Plat Merah & 47,38 \\
3 & Plat Kuning & 52,62 \\
\hline \multicolumn{2}{|c|}{ Rata - rata } & 56,51 \\
\hline
\end{tabular}




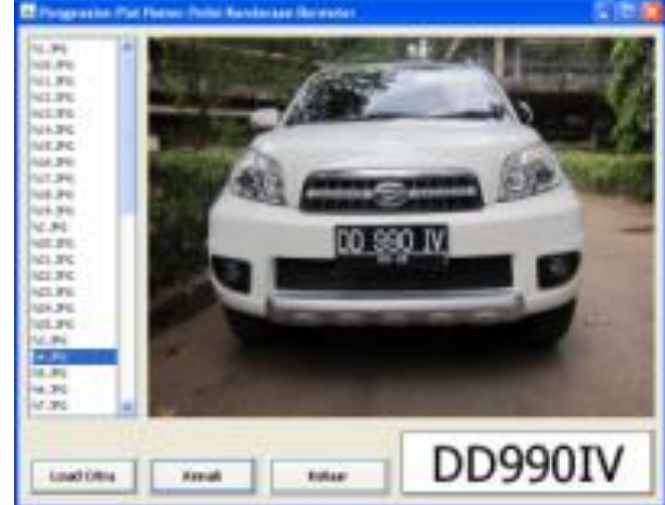

Gambar 10. Hasil Pengenalan

Karakter dari citra h4.jpg

Salah satu sampel citra kendaraan yang dapat dikenali secara sempurna dapat dilihat pada gambar 10. Untuk kasus dimana sistem dapat mengenali plat nomor tetapi karakternya tidak sempurna, faktor yang mempengaruhi hal ini diantaranya karena adanya kemiripan antara beberapa jenis huruf dengan angka seperti $\mathrm{B}$ dengan $8 ; \mathrm{D}, \mathrm{O}, \mathrm{Q}$ dengan 0 ; I dengan 1; G dengan 6; $S$ dengan 5 dan $Z$ dengan 7. Untuk plat Indonesia karakter yang pasti hanya terdapat pada digit pertama yaitu selalu didahului dengan huruf.

\section{KESIMPULAN DAN SARAN}

\section{Kesimpulan}

a. Secara umum sistem dapat mengenali karakter plat nomor polisi dari ketiga jenis plat nomor polisi kendaraan bermotor

b. Keberhasilan pada satu tahap dalam sistem pengenalan plat nomor polisi kendaraan bermotor menentukan keberhasilan pada tahap berikutnya, adapun tahapan tahapan tersebut adalah Pengolahan Citra, Penentuan Region of Interest (ROI), Segmentasi Karakter dan Pengenalan Karakter.

c. Persentase rata - rata keberhasilan sistem pada setiap tahap untuk ketiga jenis plat hitam, merah dan kuning adalah : (1)Tahap Penentuan ROI sebesar 96,67\%; (2). Tahap Segmentasi Karakter sebesar $88,11 \%$,(3).Tahap Pengenalan Karakter sebesar $53,51 \%$ sehingga secara umum persentase rata - rata keberhasilan sistem sebesar 79,43\%.

\section{Saran}

1. Persentasi terendah pada sistem pengenalan plat nomor polisi kendaraan bermotor adalah pada tahap pengenalan karakter, diharapkan adanya pengembangan dan perbaikan di tahap ini agar sistem dapat mengenali karakter dengan lebih baik.

2. Diharapkan adanya pengembangan sistem perangkat keras yang dapat mengatur tingkat iluminasi dan zooming maupun capture dari kendaraan yang sedang bergerak.

3. Diharapkan pengembangan lebih lanjut dari sistem pengenalan plat nomor polisi kendaraan bermotor sehingga dapat diimplementasikan secara nyata.

\section{DAFTAR PUSTAKA}

Martinsky,O. 2007. Algoritmic and Mathematical Principle of Automatic Number Plate Recognition Sistems. Thesis. Information Technology. Detartement of Intelegent Sistem. BRNO University.

Purnomo, H. Mauridhi dan A. Muntasa. 2010. Konsep Pengolahan Citra Digital dan Ekstraksi Fitur. Edisi Pertama. Graha Ilmu. Yogyakarta

Putra, D. 2010. Pengolahan Citra Digital. Andi Offset. Yogyakarta

Suarga. 2008. Dasar Pemrograman Komputer (dalam bahasa JAVA). Penerbit ANDI. Yogyakarta.

Zunino, R and S. Rovetta. 2000. Vector Quantization for License - Plate Location and Image Coding. IEEE Transactions Industrial Electronics Vol.47 No.1. 